\title{
Aloe vera downregulates LPS-induced inflammatory cytokine production and expression of NLRP3 inflammasome in human macrophages
}

\author{
Marietta M. Budai ${ }^{\mathrm{a}}$, Aliz Varga ${ }^{\mathrm{a}}$, Sándor Milesz ${ }^{\mathrm{b}}$, József Tőzsér ${ }^{\mathrm{c}}$, Szilvia Benkő ${ }^{\mathrm{a}, *}$ \\ a Department of Physiology, Medical and Health Science Center, Faculty of Medicine, University of Debrecen, Nagyerdei Blv. 98, Debrecen H-4012, Hungary \\ ${ }^{\mathrm{b}}$ FLP Hungary, Szondi Street 34, Budapest H-1067, Hungary

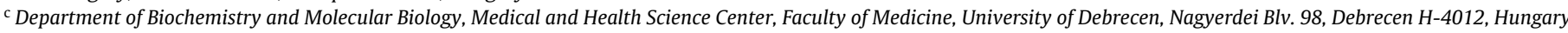

\section{A R T I C L E I N F O}

\section{Article history:}

Received 2 April 2013

Received in revised form 11 April 2013

Accepted 14 May 2013

Available online 1 August 2013

\section{Keywords:}

Aloe vera

Macrophage

Nlrp3 inflammasome

Cytokine

P2X7R

Signal transduction

\begin{abstract}
A B S T R A C T
Aloe vera has been used in traditional herbal medicine as an immunomodulatory agent inducing antiinflammatory effects. However, its role on the IL- $1 \beta$ inflammatory cytokine production has not been studied. IL-1 $\beta$ production is strictly regulated both at transcriptional and posttranslational levels through the activity of Nlrp3 inflammasome. In this study we aimed to determine the effect of Aloe vera on the molecular mechanisms of Nlrp3 inflammasome-mediated IL-1 $\beta$ production in LPS-activated human THP-1 cells and monocyte-derived macrophages. Our results show that Aloe vera significantly reduced IL-8, TNF $\alpha$, IL- 6 and IL-1 $\beta$ cytokine production in a dose dependent manner. The inhibitory effect was substantially more pronounced in the primary cells. We found that Aloe vera inhibited the expression of pro-IL-1 $\beta$, Nlrp3, caspase- 1 as well as that of the P2X7 receptor in the LPS-induced primary macrophages. Furthermore, LPS-induced activation of signaling pathways like NF- $\mathrm{B}$, p38, JNK and ERK were inhibited by Aloe vera in these cells.

Altogether, we show for the first time that Aloe vera-mediated strong reduction of IL- $1 \beta$ appears to be the consequence of the reduced expression of both pro-IL-1 $\beta$ as well as Nlrp3 inflammasome components via suppressing specific signal transduction pathways. Furthermore, we show that the expression of the ATP sensor P2X7 receptor is also downregulated by Aloe vera that could also contribute to the attenuated IL-1 $\beta$ cytokine secretion. These results may provide a new therapeutic approach to regulate inflammasome-mediated responses.
\end{abstract}

(c) 2013 Elsevier Ltd. All rights reserved.

\section{Introduction}

Inflammatory responses are characterized by a sequence of complex, interrelated events that ultimately lead to the recruitment of phagocytes, the elimination of harmful particles and the initiation of tissue repair. These events rely on an orchestrated network of cellular components including soluble factors like that of

Abbreviations: ATP, adenosine-5'-triphosphate; ASC, apoptosis-associated speck-like protein containing a caspase recruitment domain; ELISA, enzymelinked immunosorbent assay; ERK, extracellular-signal-regulated kinase; GM-CSF, granulocyte-macrophage colony stimulating factor; $\operatorname{IkB} \alpha$, nuclear factor of kappa light polypeptide gene enhancer in B-cells inhibitor alpha; IL-1 $\beta$, interleukin-1 $\beta$; IL-6, interleukin-6; IL-8, interleukin-8; JNK, c-Jun N-terminal kinase; LPS, lipopolysaccharide; MAPK, mitogen-activated protein kinase; MF, macrophage; MMP-9, Matrix metallopeptidase 9; NF-кB, nuclear factor kappalight-chain-enhancer of activated B cells; NLRP3, NOD-like receptor family pyrin domain-containing 3; PMA, phorbol myristate acetate; P2X7R, P2X purinergic receptor 7; RT-PCR, real-time polymerase chain reaction; THP-1, human acute monocytic leukemia cell line; TLR4, Toll-like receptor 4; TNF $\alpha$, tumor necrosis factor-alpha.

* Corresponding author. Tel.: +36 52255 575; fax: +36 52255116.

E-mail address: szbenko@gmail.com (S. Benkő). the inflammatory cytokines. Among pro-inflammatory cytokines, IL-1 $\beta$ functions as a "master" cytokine that has an indispensable role in orchestrating effective innate and adaptive immune responses (Dinarello, 2009). It induces the activation of various cell types like phagocytes, epithelial and endothelial cells, helps the activation and polarization of T-lymphocytes, and enhances the expression of further pro-inflammatory cytokines like that of the IL-6, TNF $\alpha$ (Ciraci et al., 2012; Dinarello, 1997, 2011a). However, prolonged production of IL-1 $\beta$ can lead to severe tissue and organ damages as it is reported in several chronic inflammatory and autoimmune diseases (Dinarello, 2011b; Gabay et al., 2010).

Production of IL-1 $\beta$ strongly depends on the function of multiprotein complexes called inflammasomes. Among inflammasomes, one of the most intensively studied ones is the Nlrp3 inflammasome that contains an Nlrp3 sensor, an ASC adaptor and a caspase-1 enzyme (Cassel et al., 2009; De Nardo and Latz, 2011; Menu and Vince, 2011). Due to its critical function in inflammatory responses, and as part of the safety feature of the immune system, IL- $1 \beta$ production is regulated at various levels and requires distinct signals. Some of these signals induce the expression of the inactive proIL-1 $\beta$ and Nlrp3 via the activation of NF- $\kappa B$ and stress-activated 
protein kinases such as JNK and p38 MAPK, while other signals like ATP trigger the processing of pro-IL-1 $\beta$ to mature IL- $1 \beta$ by caspase-1 (Franchi et al., 2012; Gross et al., 2011; Lopez-Castejon and Brough, 2011; Rathinam et al., 2012; Schroder et al., 2012). ATP induces Nlrp3 inflammasome activation through stimulation of purinergic receptor P2X ligand-gated ion channel 7 (P2X7) which induces $\mathrm{K}^{+}$efflux.

Aloe vera is a medical plant used traditionally in diverse therapeutic applications. The beneficial properties of the plant have been ascribed to the inner, colorless leaf gel that can function both orally and topically as an active immunomodulator. The gel of Aloe vera has been reported to stimulate wound-healing and skin hydration, induce hematopoiesis, and possess anti-diabetic, anti-carcinogenic, antimicrobial, anti-oxidant as well as anti-inflammatory activities (Dat et al., 2012; Hamman, 2008a; Im et al., 2010; Surjushe et al., 2008; Vazquez et al., 1996).

Over 75 active components have already been identified in Aloe vera leaf gels (Hamman, 2008b), and some of them have been implicated as immunomodulatory compounds based on animal studies. Complex carbohydrates were shown to increase macrophage phagocytosis by increasing NO production (Karaca et al., 1995). Aloe-emodin, an anthraquinon compound has been shown to promote natural killer cell activity and macrophage phagocytosis (Yu et al., 2006). Aloins and low molecular fractions of Aloe also containing them together with other anthraquinons might influence the immune response by inhibiting $\mathrm{H}_{2} \mathrm{O}_{2}$ formation ('t Hart et al., 1990) and/or by inhibiting proteases (Barrantes and Guinea, 2003).

The anti-inflammatory activity of Aloe vera has been evaluated in a number of inflammation models. It has been shown that in experimental animals Aloe vera reduces inflammation detected as reduced neutrophil migration and edema formation (Davis et al., 1989). In Helicobacter pylori-infected rats Aloe vera significantly reduced leukocyte adhesion and TNF $\alpha$ levels (Prabjone et al., 2006). Other studies showed that mRNA expression of colonic mucosa proinflammatory cytokines such as IL-6 and TNF $\alpha$ was significantly reduced in colitic animals fed by Aloe vera gel (Park et al., 2011). Similar effect was found in a mouse sepsis model and in a human colorectal mucosa model, in particular that treatment with Aloe vera significantly inhibited the elevation of TNF $\alpha$, IL- 6 and IL-1 $\beta$ levels (Eamlamnam et al., 2006; Langmead et al., 2004; Yun et al., 2009).

Regarding human models, the effect of Aloe vera is usually studied in skin and epidermis related disorders (Reuter et al., 2008; Vogler and Ernst, 1999). Aloe vera has recently been shown to inhibit inflammatory responses by downregulating MMP-9 in peripheral blood leukocytes (PBLs), and to reduce cytokine (TNF $\alpha$ and IL-1 $\beta$ ) production in undifferentiated THP-1 cells and PBLs (Vijayalakshmi et al., 2012; Habeeb et al., 2007). The anti-inflammatory effect of the supernatant of a commercial stabilized gel (from Forever Living Product) was found to have very similar effects to those found with a reconstituted lyophilized powder. However, to our knowledge no studies have been performed so far on the effect of Aloe vera on primary human monocyte-derived macrophages, and on the involved molecular mechanisms on its capacity to inhibit cytokine production.

Macrophages are indispensable participants of inflammatory responses and they are the main sources of pro-inflammatory cytokines including IL-1 $\beta$. In this study, we aimed to determine the anti-inflammatory effect of Aloe vera on LPS-activated THP-1 cells as well as human monocyte-derived macrophages. We show that Aloe vera significantly downregulated the expression of proinflammatory cytokines, including IL- $1 \beta$ of these cells. Also, we show that the activation of NF- $\mathrm{KB}, \mathrm{p} 38$, JNK and ERK signaling pathways is significantly inhibited by Aloe vera treatment in the activated primary macrophages. Furthermore, we show for the first time that Aloe vera could significantly inhibit the LPS-induced expression of Nlrp3 inflammasome components and that of the P2X7 receptor, a phenomenon that likely contributes to the reduced IL-1 $\beta$ production by human macrophages.

\section{Materials and methods}

\subsection{Chemicals}

The commercial Aloe vera (Aloe barbadensis Miller, Forever Living Products Ltd.) used in our experiments contained over 96\% of the gel found in the inner part of the aloe plant leaves, and was certified by the International Aloe Science Council. The product contains antioxidants like ascorbic acid $(0.2 \%)$ and tocopherol (0.004\%), preservatives as sodium benzoate and potassium sorbate (0.1-0.1\%), sweetener as sorbitol (3.2\%) as well as xanthan gum as thickener $(0.02 \%)$. To exclude the influence of these materials on the cells, we have used the solvent solution as control containing all the extra ingredients in the same concentrations as they were used in the commercial preparation. The gel was centrifuged with $2000 \mathrm{rpm}$ for $30 \mathrm{~min}$ to remove the insoluble components and obtain a clear solution. Solvent utilized for the preparation of the gel was used in the mock experiments. The supernatant of the centrifugation was used in the experiments. Ultra pure $E$. coli LPS was from InvivoGen, San Diego, CA, USA.

\subsection{THP-1 cell culture and differentiation into macrophage}

The human monocytic THP-1 cells (ATCC TIB-202) were cultured in RPMI 1640 (Sigma-Aldrich, St. Louis, MO, USA) containing $2 \mathrm{mM}$ L-glutamine and supplemented with $10 \%$ heat-inactivatedFCS, $500 \mathrm{U} / \mathrm{ml}$ penicillin-streptomycin (Life Technologies, Carlsbad, CA, USA). Differentiation of THP-1 cells was induced by incubating the cells with $0.5 \mu \mathrm{M}$ phorbol myristate acetate (InvivoGen, San Diego, CA, USA) for $3 \mathrm{~h}$, as described previously (Grahames et al., 1999). Then cells were washed three times with PBS and plated at $1.3 \times 10^{6} \mathrm{ml}^{-1}$. After $24 \mathrm{~h}$ cells were treated with $100 \mathrm{ng} / \mathrm{ml} \mathrm{LPS}$ in the absence or presence of Aloe vera.

\subsection{Isolation and cell culture of human peripheral blood monocytes}

Leukocyte-enriched buffy coats were obtained from healthy blood donors in accordance with the written approval of the Director of the National Blood Transfusion Service and the Regional and Institutional Ethics Committee of the University of Debrecen, Medical and Health Science Center (Debrecen, Hungary). The informed consent of all participating subjects was obtained. Mononuclear cells were isolated by Ficoll density gradient centrifugation and $\mathrm{CD}_{14}{ }^{+}$monocytes were separated with anti-CD14-conjugated microbeads (Miltenyi Biotec, Bergish Gladbach, Germany). Monocytes were differentiated with GM-CSF and treated with LPS as described previously (Rey-Giraud et al., 2012; van't Wout et al., 2012). Briefly, monocytes were plated in 12-well tissue culture plates $\left(1.5 \times 10^{6}\right.$ cells $\left./ \mathrm{ml}\right)$, and cultured and differentiated in RPMI 1640 (Sigma-Aldrich, St. Louis, MO, USA) containing 2 mM L-glutamine and supplemented with $10 \%$ heat-inactivated-FCS, $500 \mathrm{U} / \mathrm{ml}$ penicillin-streptomycin (Life Technologies, Carlsbad, CA, USA) and $80 \mathrm{ng} / \mathrm{ml} \mathrm{GM-CSF} \mathrm{(Gentaur} \mathrm{Molecular} \mathrm{Products,} \mathrm{Brussels,}$ Belgium). On day 3, GM-CSF was replenished (Juliana et al., 2012). On day 6 , macrophages were activated with LPS $(500 \mathrm{ng} / \mathrm{ml})$ in the absence or presence of Aloe vera for $24 \mathrm{~h}$, followed by treatment with ATP (5 mM) (Sigma-Aldrich, St. Louis, MO, USA). 


\subsection{Cytotoxicity assay}

THP-1 macrophages and monocyte-derived macrophages were plated in 96 well plates at a concentration of $2 \times 10^{5}$ cells/well. Cells were incubated with different amounts of the solvent or with Aloe vera $(1 \%, 3 \%, 5 \%, 10 \%, v / v)$ for $24 \mathrm{~h}$ at $37^{\circ} \mathrm{C}$. At the end of treatment, the medium from control and Aloe vera-treated cultures were discarded and $100 \mu$ l of MTT [3-(4.5-dimethylthiazol-2-yl)-25-diphenyltetrazolium bromide] $(0.5 \mathrm{mg} / \mathrm{ml})$ containing PBS was added to each well. The cells were incubated for $2-4 \mathrm{~h}$ at $37^{\circ} \mathrm{C}$. Finally the MTT crystals were dissolved by adding $100 \mu \mathrm{l}$ of solubilization solution ( $81 \mathrm{v} / \mathrm{v} \%$ isopropanol, $9 \mathrm{v} / \mathrm{v} \% 1 \mathrm{M} \mathrm{HCl}, 10 \mathrm{v} / \mathrm{v} \%$ TritonX-100) and the formazan dye was measured in a microplate reader (BioTek Instruments, Winooski, VT, USA) at $550 \mathrm{~nm}$.

\section{5. $R N A$ preparation and $R T-P C R$}

Macrophages were treated with Aloe vera in the presence or absence of LPS for $24 \mathrm{~h}$. Total RNA was isolated by TriReagent (Molecular Research Center, Inc., Cincinnati, OH, USA) according to the manufacturer's instructions. The concentration and homogeneity of RNA preparations were determined by a spectrophotometer (NanoDrop ND1000; Promega Biosciences, Madison, WI, USA). Standardized amounts of RNA were digested with DNase (Ambion Inc., Austin, TX, USA) then first-strand cDNA was synthesized using SuperScript II First-strand Reverse Transcriptase and oligo dT primers (Invitrogen, Carlsbad, CA, USA).

\subsection{Real-time quantitative PCR}

Real time (RT) analyses of cDNA samples were performed using an ABI Prism 7900HT machine (Applied Biosystems, Foster City, CA, USA). For amplification, all oligo mixes were purchased from Applied Biosystems (IL-1 $\beta$ Hs00174097_m1, NLRP3 Hs00918082_m1, caspase-1 Hs00354836_m1, P2X7R Hs00175721_m1). Taq DNA Polymerase (Fermentas, Vilnius, Lithuania) was used for amplification, and Rox Reference Dye (Invitrogen, Carlsbad, CA, USA) was used for normalization of fluorescent reporter signal. RT-PCR was performed in $12.5 \mu \mathrm{l}$ reaction mixture containing $62.5 \mathrm{ng}$ of cDNA. The amplification was carried out as follows: 1 cycle for denaturation $\left(95^{\circ} \mathrm{C}\right.$ for $1 \mathrm{~min}$ ) followed by 40 cycles for two-stage PCR $\left(95^{\circ} \mathrm{C}\right.$ for $12 \mathrm{~s}$ and $60^{\circ} \mathrm{C}$ for $\left.1 \mathrm{~min}\right)$. The relative changes in gene expression were calculated by the $\Delta C_{\mathrm{t}}$ method using cyclophilin as control.

\subsection{Western blot analysis}

Macrophages were treated with Aloe vera in the presence or absence of LPS for the indicated time. Proteins were separated by SDS-PAGE and transferred onto nitrocellulose membranes. Membranes were then blocked with $5 \%$ non-fat milk, washed briefly, incubated with primary antibodies at $4{ }^{\circ} \mathrm{C}$ overnight. Pro-IL-1 $\beta$ and procaspase- 1 antibodies were from Santa Cruz Biotechnology, CA, USA, cleaved IL-1 $\beta$ antibody was from Cell Signaling Technology, Danvers, MA, USA, NLRP3 antibody was from ENZO Life Sciences Inc., Farmingdale, NY, USA, P2X7R antibody was from Alomone labs, Jerusalem, Israel, p-ERK1/2 was from Sigma-Aldrich, St. Louis, MO, USA, p-IкB $\alpha$, p-p38 MAP kinase and p-SAPK/JNK antibodies were obtained from Cell Signaling Technology, Danvers, MA, USA. Primary antibodies were incubated with corresponding horseradish peroxidase-conjugated secondary antibodies from Amersham Biosciences, Piscataway, $\mathrm{NJ}$ for $1 \mathrm{~h}$ at room temperature. Proteins were visualized by Supersignal West-Pico peroxide/luminol enhancer solution from Pierce, Rockford, IL, USA. Equal amount of protein

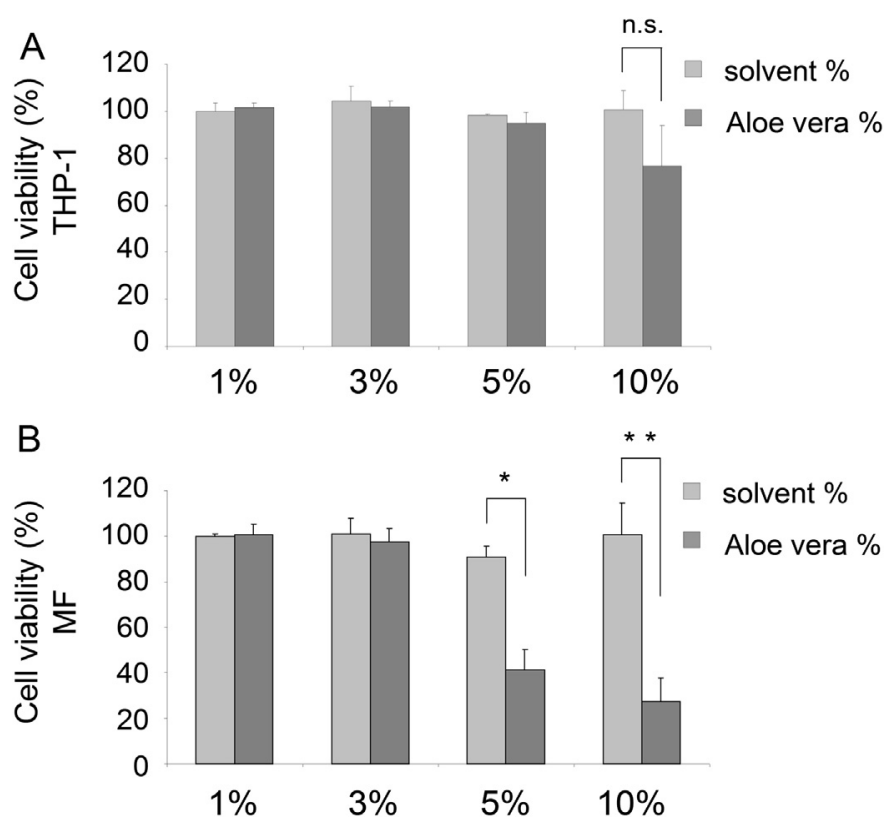

Fig. 1. Determination of cell viability. PMA-differentiated THP-1 macrophages (A) and primary human monocyte-derived macrophages (MF) (B) were treated with increasing concentration of solvent or Aloe vera. Results were obtained from three independent experiments with three replicates. Mean \pm SD values are provided as ${ }^{*} p<0.01,{ }^{* *} p<0.001$.

sample loading was verified by detecting $\beta$-actin (Sigma-Aldrich, St. Louis, MO, USA) protein expression.

\subsection{Enzyme-linked immunosorbent assay (ELISA)}

Supernatants collected from macrophages were evaluated for production of cytokines (IL-1 $\beta$, IL-6, TNF $\alpha$ ) and chemokine IL- 8 using ELISA kits (BD Biosciences, San Diego, CA, USA) according to the manufacturer's instructions. The minimum detectable doses are $0.8 \mathrm{pg} / \mathrm{ml}$ for IL-8, $2 \mathrm{pg} / \mathrm{ml}$ for TNF $\alpha, 2.2 \mathrm{pg} / \mathrm{ml}$ for IL-6 and $0.8 \mathrm{pg} / \mathrm{ml}$ for IL-1 $\beta$.

\subsection{Statistical analysis}

Significant differences between mean values were evaluated using a Student's $t$-test. Data presented as mean \pm SD.

\section{Results}

\subsection{Human monocyte-derived macrophages are substantially} more sensitive for Aloe treatment than THP-1 macrophages

First, we aimed to determine the cytotoxic effect of Aloe vera on THP-1 macrophage-like cells and on the human monocyte-derived macrophages (MFs). For this reason cells were treated with an increasing amount of Aloe vera (1-10v/v\%) for $24 \mathrm{~h}$ and cell viability was measured using an MTT assay. We found that using Aloe vera up to $10 \mathrm{v} / \mathrm{v} \%$ did not affect significantly the viability of THP1 cells, although $10 \mathrm{v} / \mathrm{v} \%$ Aloe vera showed some moderate (up to $15 \%$ ) cell death in these cells (Fig. $1 \mathrm{~A}$ ). On the other hand, $5 \mathrm{v} / \mathrm{v} \%$ of Aloe vera already resulted in more than $50 \%$ cell death of primary macrophages and $10 \mathrm{v} / \mathrm{v} \%$ of Aloe vera led to more than $70 \%$ death of these cells (Fig. 1B). These results show that human primary MFs are substantially more sensitive for Aloe vera treatment than THP-1 cell line. 


\section{THP-1}

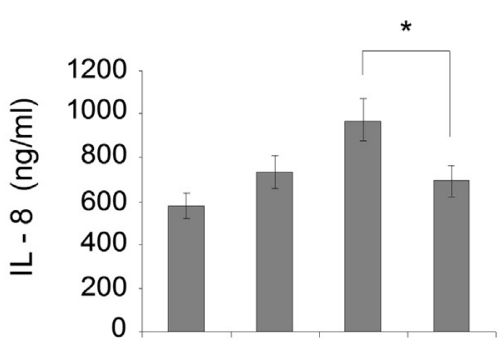

$\begin{array}{rcccc}\text { Aloe vera } & - & 10 \% & - & 10 \% \\ \text { LPS } & - & - & + & +\end{array}$

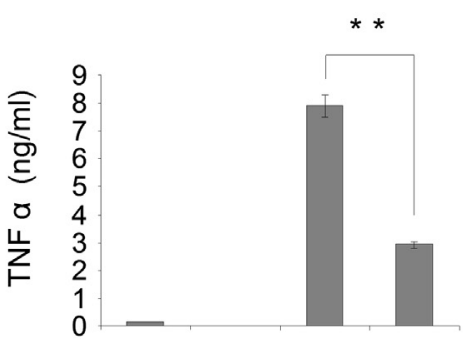

$\begin{array}{rcccc}\text { Aloe vera } & - & 10 \% & - & 10 \% \\ \text { LPS } & - & - & + & +\end{array}$

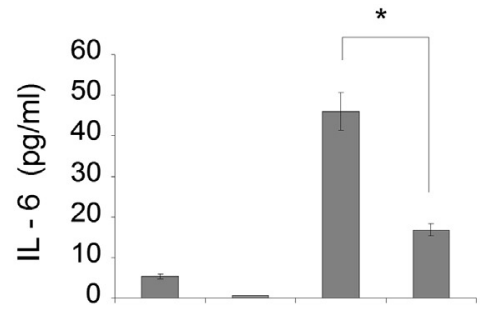

Aloe vera - $10 \% \quad-\quad 10 \%$

LPS

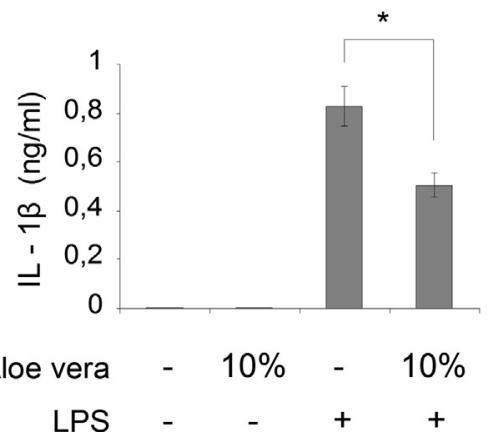

MF

IL-8

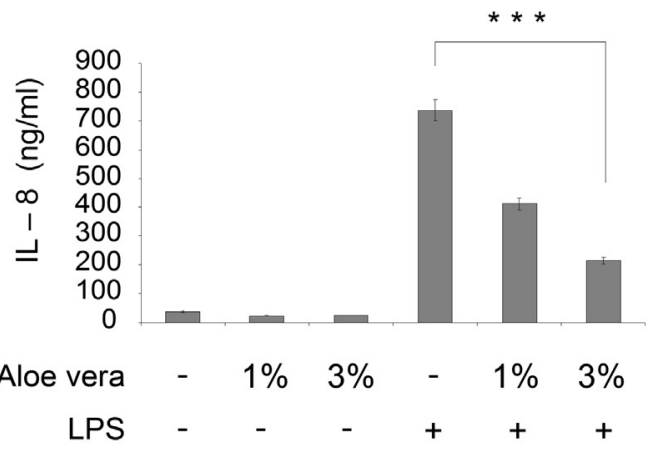

TNFa

IL-6
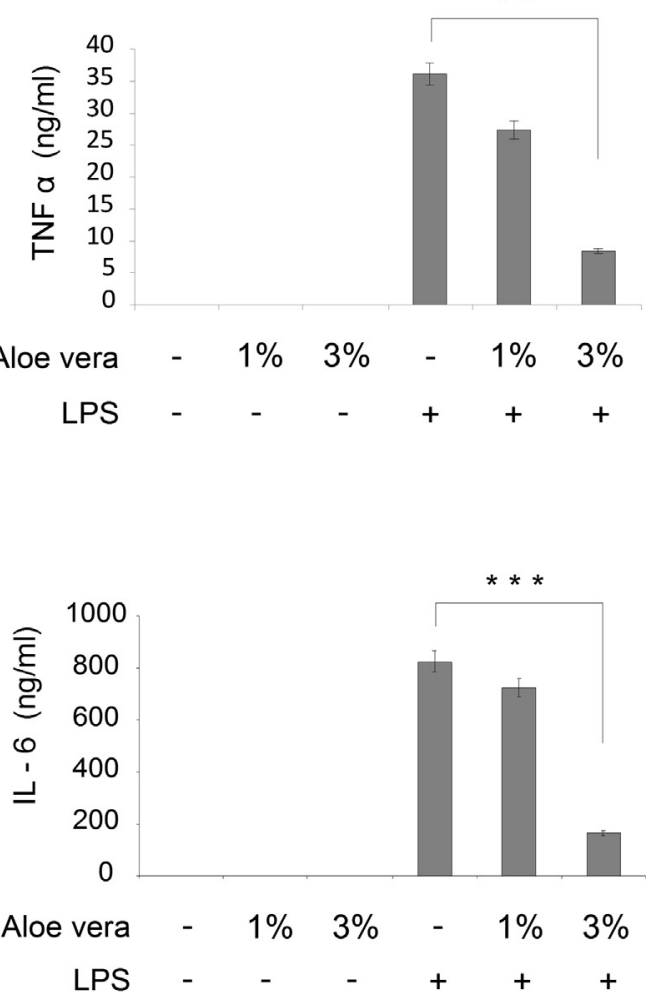

IL-1 $\beta$

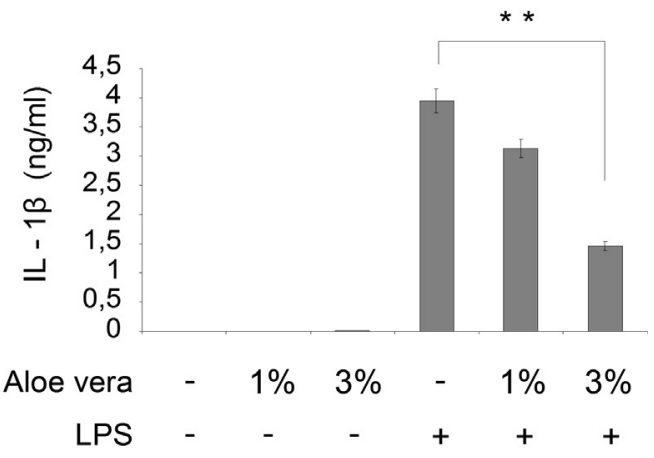

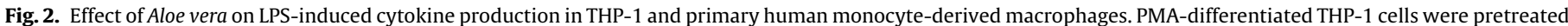

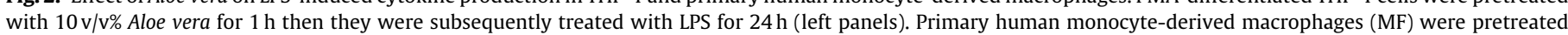

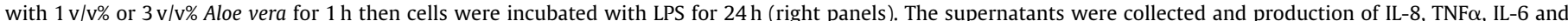

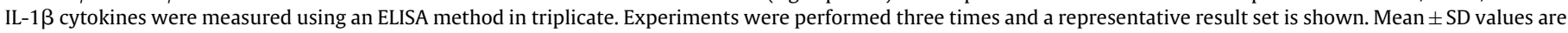
provided as ${ }^{*} p<0.05,{ }^{* *} p<0.005,{ }^{* * *} p<0.0005$. 


\subsection{Aloe vera significantly decreases cytokine production of LPS-activated macrophages}

LPS is a TLR4 specific agonist that has been described to be a strong inducer of inflammatory responses in macrophages. To see whether cytokine production is influenced by Aloe vera, THP1 cells and primary human MFs were treated with an increasing amount of Aloe vera in the presence or absence of LPS and cytokine secretion was measured from the medium of the cells using ELISA methods. In good agreement with pervious reports, we found that LPS treatment significantly induced the production of IL-8, TNF $\alpha$, IL-6 and IL-1 $\beta$ pro-inflammatory cytokines (Fig. 2). While Aloe vera itself had only a non-significant effect on the production of the afore-mentioned cytokines in THP-1 cells and had no effect on the primary macrophages, it significantly reduced the LPS-induced secretion of these cytokines in both cell types in a concentration-dependent manner (Fig. 2). Furthermore, our results also demonstrated that while in the case of MFs the highest nontoxic concentration of Aloe vera $(3 \mathrm{v} / \mathrm{v} \%)$ resulted in more than $70 \%$ reduction in cytokine production, the attenuation of cytokine production was less pronounced in THP-1 cells even with the $10 \mathrm{v} / \mathrm{v} \%$ Aloe vera treatment. Therefore, to explore the molecular basis of the observations, we have used monocyte-derived primary macrophages in the further experiments.

\subsection{Aloe vera attenuates the LPS-induced expression of IL-1 $\beta$}

Secretion of IL-1 $\beta$ requires the induction of pro-IL-1 $\beta$ expression followed by its proteolytic processing to mature IL- $1 \beta$ by the
Nlrp3 inflammasome complex. To identify which step of this process is influenced by Aloe vera, MFs were treated with $3 \mathrm{v} / \mathrm{v} \%$ of Aloe vera in the presence or absence of LPS and expression of proIL-1 $\beta$ and production of mature IL-1 $\beta$ was studied from the cell lysates by Western blot method (Fig. 3A). While in good agreement with the ELISA results Aloe vera alone did not have an effect on pro-IL-1 $\beta$ expression, LPS strongly induced it, resulting in the intracellular appearance of both the pro-IL-1 $\beta$ as well as processed IL-1 $\beta$ proteins. Also, in good agreement with the ELISA results, Aloe vera treatment of the LPS-induced primary macrophages significantly decreased the amount of both pro-IL-1 $\beta$ and IL-1 $\beta$ forms in the cell lysates (Fig. 3A). The substantial increase of the IL-1 $\beta$ expression following the LPS treatment was at least partly due to the enhanced transcription of the pro-IL-1 $\beta$ gene, as it is demonstrated by the quantitative RT-PCR analysis of RNA purified from the treated cells (Fig. 3B). Nevertheless, Aloe vera treatment reduced the LPS-triggered gene transcription in a dose-dependent manner (Fig. 3B). The dramatically induced transcription of pro-IL-1 $\beta$ in the LPS-treated THP-1 cells was also significantly reduced in the presence of $10 \mathrm{v} / \mathrm{v} \%$ Aloe vera (data not shown).

\subsection{Aloe vera attenuates LPS-induced expression of Nlrp3 and caspase-1 in human primary macrophages}

LPS-induced production of IL-1 $\beta$ requires the presence and function of Nlrp3 inflammasome. To see whether the expression of Nlrp3 inflammasome components is affected by Aloe vera, primary macrophages were activated with LPS in the presence or absence of Aloe vera and the transcription as well as protein

A

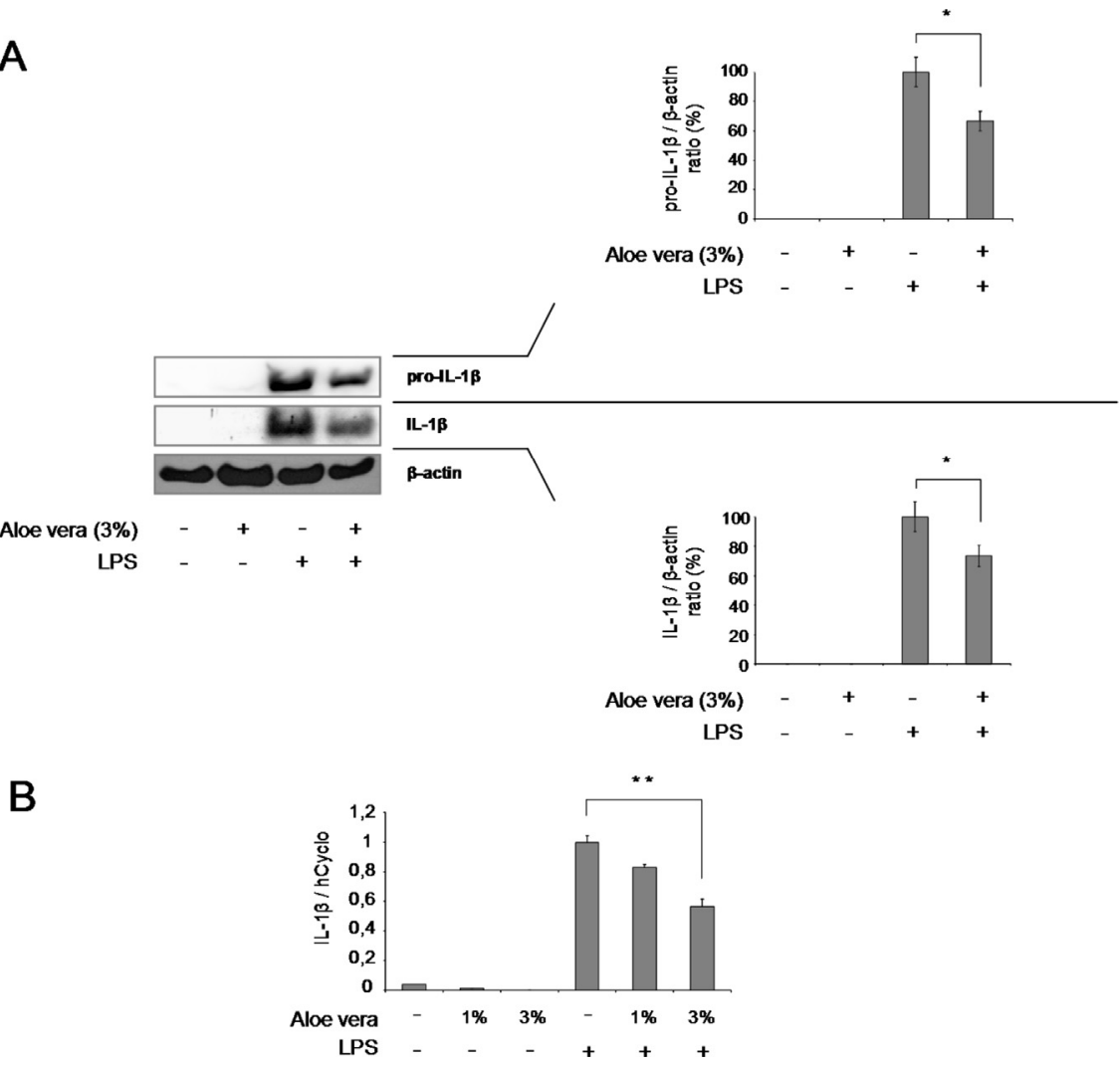

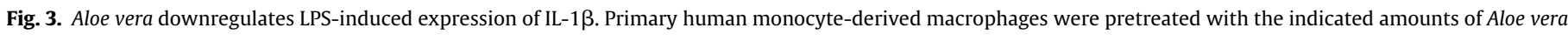

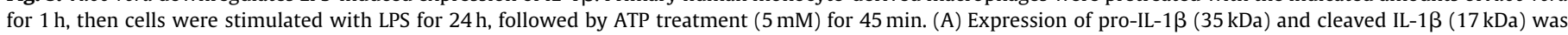

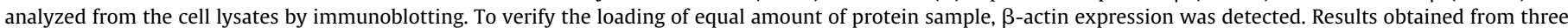

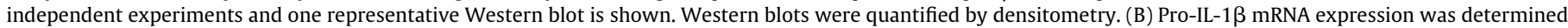

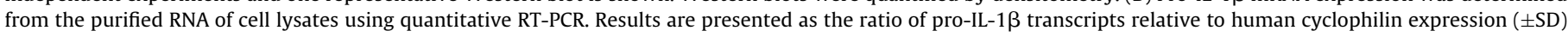
measured in triplicate. ${ }^{*} p<0.1,{ }^{* *} p<0.01$ 
A

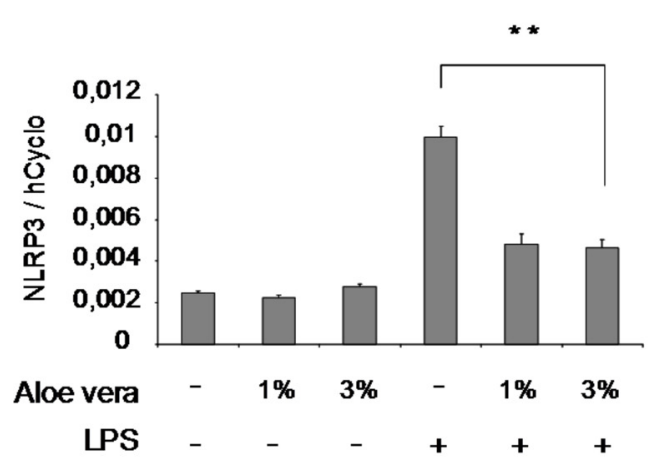

C

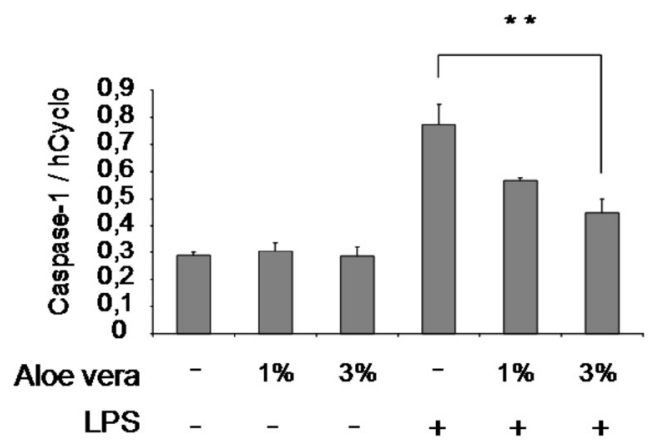

B
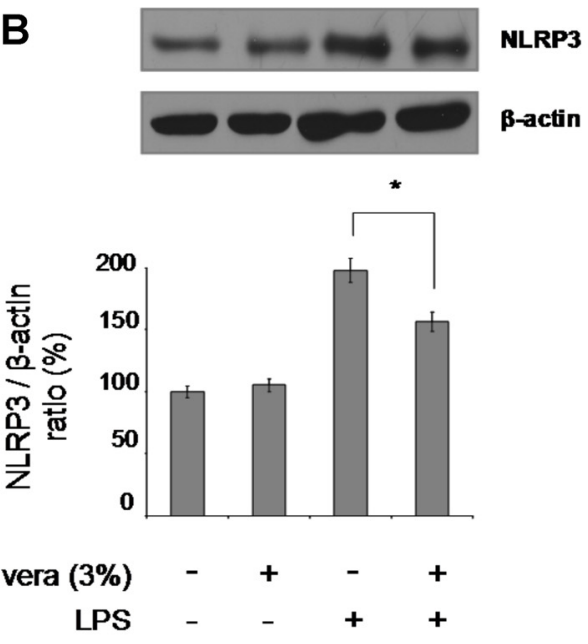

D

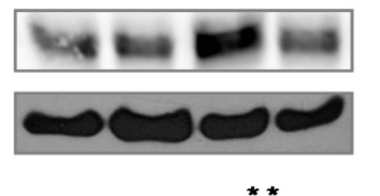

procaspase-1

B-actin

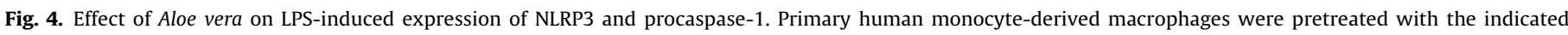

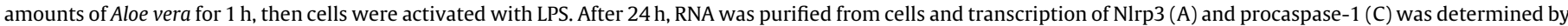

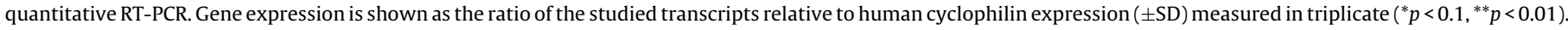

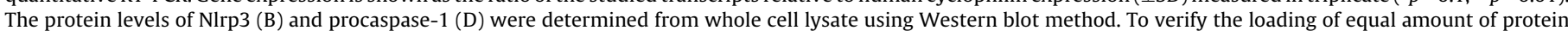

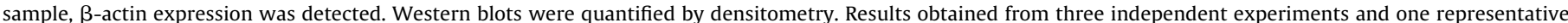
Western blot are shown. Mean \pm SD values of three independent experiments are shown. ${ }^{*} p<0.1,{ }^{* *} p<0.01$.

expression of Nlrp3 and procaspase-1 was studied using quantitative RT-PCR and Western blot methods. Our results showed that LPS significantly induced the expression of NLRP3 sensor and caspase1 both at mRNA and protein level (Fig. 4). Except the moderate decrease of caspase-1 protein, Aloe vera treatment alone did not affect the transcription and the expression of the studied inflammasome components. However, it substantially downregulated their LPS-induced transcription, and this effect was also detectable at the protein level (Fig. 4).

\subsection{Aloe vera downregulates the LPS-induced expression of P2X7 receptor}

Nlrp3 inflammasome activation and IL-1 $\beta$ release in macrophages require the presence of ATP that is sensed by the membrane-localized P2X7 receptors. To see whether Aloe vera treatment would influence the expression of ATP sensor P2X7 receptor, macrophages were treated with Aloe vera in the absence or presence of LPS. Our results show that the expression of P2X7 receptor was strongly induced by LPS (Fig. 5). Furthermore, while Aloe vera alone had a minor effect on the expression of unstimulated cells, it dramatically reduced the LPS-activated expression of $\mathrm{P} 2 \mathrm{X} 7$ receptor expression reducing it almost to the basal level.
3.6. Aloe vera inhibits the LPS-induced activation of $N F-\kappa B, p 38$, JNK and ERK signal transduction pathways

LPS induces a network of signaling pathways that, as a consequence, influence the expression of several genes. To explore whether Aloe vera has an effect on LPS-induced activation of signal transductions, macrophages were treated with LPS in the presence or absence of Aloe vera and the time-dependent phosphorylation of key signaling molecules of the NF- $\mathrm{B}, \mathrm{p} 38$, JNK, and ERK signaling pathways was followed by Western blot technique. Studying the activation of NF- $\mathrm{B}$ pathway, we found that LPS induced a time-dependent phosphorylation of $\mathrm{IkB} \alpha$ that peaked at 30 min (Fig. 6). Treatment of macrophages with Aloe vera completely abolished the LPS-induced phosphorylation of $\operatorname{IkB} \alpha$. Unlike $\operatorname{IkB} \alpha$, p38 was already strongly phosphorylated 10 min after LPS treatment that appeared to be slowly decreasing in the studied 60 min period, however, this phosphorylation was also prevented by Aloe vera treatment. Similar results were obtained for ERK $1 / 2$ phosphorylation, and the weak but early (10 min) phosphorylation of SAPK/JNK was also prevented by Aloe vera treatment. Altogether these results show that Aloe vera treatment results in the broad spectrum of inhibition of signal transduction pathways. 
A

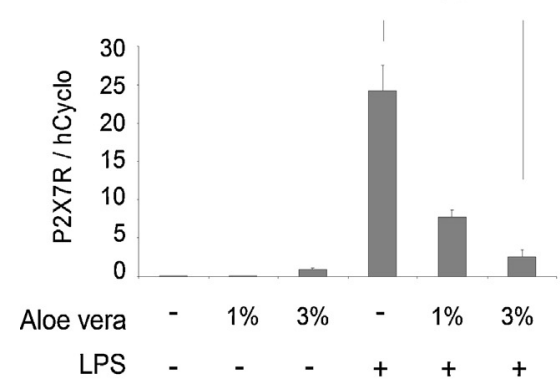

B
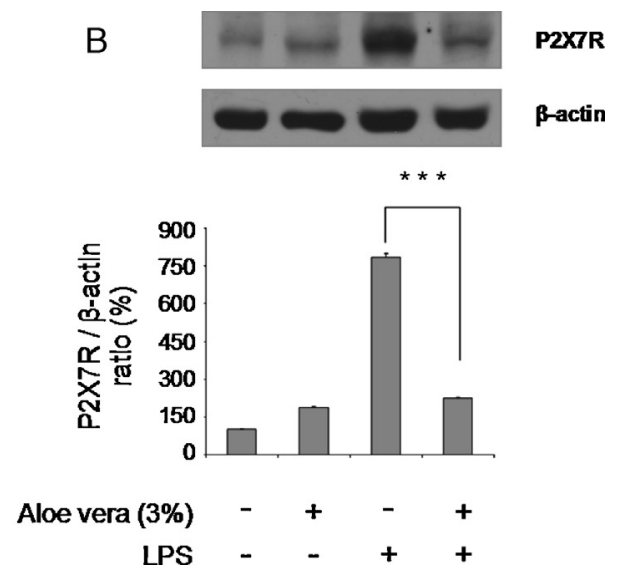

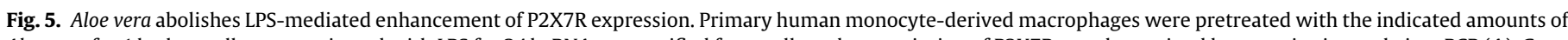

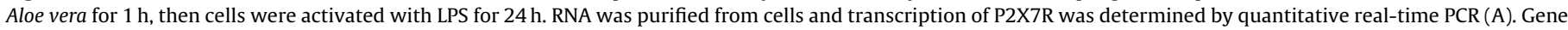

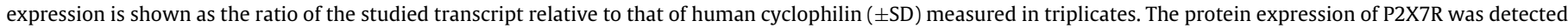

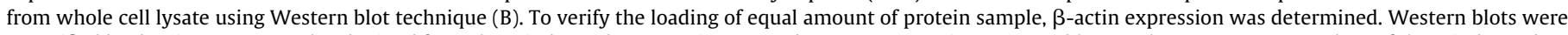

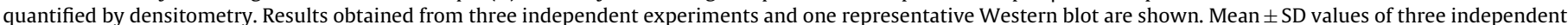
experiments are shown. ${ }^{* *} p<0.005,{ }^{* * *} p<0.0005$.

\section{Discussion}

Though Aloe vera has been used traditionally as a curative agent in diverse health issues, the detailed molecular mechanism of its effect is only being explored in recent years. In this study we used stabilized Aloe vera gel supernatant as a clear, well-defined solution to examine its effect on the expression of inflammatory cytokines and that of the components of Nlrp3 inflammasome in LPS-activated macrophages. We have evaluated the cytotoxic effect of Aloe vera on human macrophage-like THP-1 cells as well as on human monocyte-derived macrophages. In good agreement with previous experiments where $10 \mathrm{v} / \mathrm{v} \%$ Aloe vera solution from the same source we have used was applied to THP-1 cells, we have demonstrated that $10 \mathrm{v} / \mathrm{v} \%$ Aloe vera did not cause significant degree of cell loss (Duansak et al., 2003). On the other hand, $3 \mathrm{v} / \mathrm{v} \%$ of Aloe vera was the highest concentration in our experiments that did not result cytotoxic effect on human monocyte-derived macrophages. These differences might reflect that primary cells are more sensitive for these treatments than immortalized/tumor cell lines.

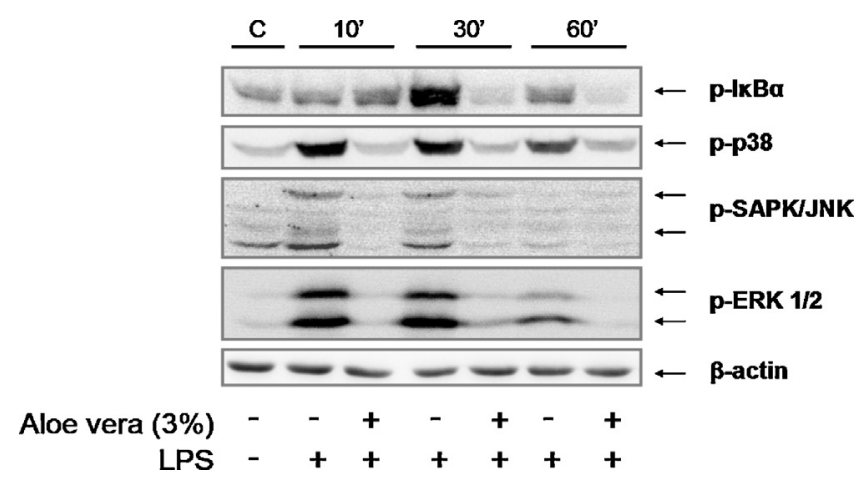

Fig. 6. Effect of Aloe vera on LPS-induced signal transductions. Primary human monocyte-derived macrophages were pretreated with Aloe vera for $1 \mathrm{~h}$, then cells were activated with LPS for the indicated times. The phospohorylation of IкB $\alpha$, p38 MAPK, SAPK/JNK and ERK was analyzed from the cell lysates by Western blot method. To verify the loading of equal amount of protein sample, $\beta$-actin expression was also detected. Results obtained from three independent experiments and one representative Western blot are shown.
LPS treatment of human macrophages strongly induces the production of pro-inflammatory cytokines as part of the innate immune response. Our results show that Aloe vera treatment significantly down-regulated LPS-induced IL-8, TNF $\alpha$, IL-6, and IL-1 $\beta$ inflammatory cytokine production in a concentration dependent manner in both THP-1 cells and primary macrophages. These results are in a good agreement with studies showing antiinflammatory effects of Aloe vera in animal models without molecular explanation or showing effect on IL-1 $\beta$ and TNF $\alpha$ production in non-differentiated THP-1 cells (Prabjone et al., 2006; Park et al., 2011; Yun et al., 2009; Vijayalakshmi et al., 2012; Habeeb et al., 2007; Duansak et al., 2003). It should be noted, that not only the cytotoxic sensitivity of primary macrophages was higher than that of THP-1 cells, but also the susceptibility toward Aloe-mediated down-regulation was more pronounced in these cells. Immortalized cells, such as the acute monocytic leukemia-derived THP-1 cell line, can possess genetic and morphologic characteristics and develop resistance to death-inducing effects that would explain the observed differences between the two cell types regarding their viability and cytokine production. For this reason, and to obtain results close to in vivo status, our further studies on the molecular characterization of the Aloe's effects on IL-1 $\beta$ production focused on primary macrophages.

The production of IL-1 $\beta$ pro-inflammatory cytokine is a process that involves strictly regulated steps. It requires a "priming" stimulus that induce the expression of pro-IL-1 $\beta$ and that of the inflammasome components; furthermore, it requires stimuli that lead to the assembly and activation of inflammasome complex and ultimately to the cleavage of pro-IL-1 $\beta$ to its active IL- $1 \beta$ form (Vazquez et al., 1996; Bauernfeind et al., 2009). Our results show that the LPS-induced transcription of pro-IL-1 $\beta$ is significantly attenuated by Aloe vera in primary macrophages. A similar tendency was found by Western blot analysis of primary macrophage cell lysates: the protein levels of intracellular pro-IL-1 $\beta$ and cleaved IL-1 $\beta$ were lower in the LPS-activated Aloe vera-treated cells compared to the LPS-treated ones. Moreover, while the LPS-induced expression of Nlrp3 was moderately down-regulated, the expression of procaspase-1 was significantly down-regulated by Aloe vera both at mRNA and protein levels. Since LPS-induced IL-1 $\beta$ production requires the presence and function of Nlrp3 inflammasome, these results show that the decreased level of IL- $1 \beta$ cytokine detected in the supernatant after Aloe vera treatment may be the 
consequence of attenuated expression of not only the pro-IL-1 $\beta$ but the inflammasome components as well.

Unlike monocytes for which LPS treatment itself is sufficient for IL-1 $\beta$ production and release, macrophages require ATP supplementation for IL-1 $\beta$ secretion (Netea et al., 2009). Exogenous ATP recognized by P2X7 receptor subsequently results in Nlrp3 inflammasome activation due to the changes of cytosolic ion concentrations. Our results show that LPS treatment strongly induces P2X7 receptor expression both at transcriptional and translational level. However, Aloe vera treatment completely abolished the effect of LPS induction on the expression of the receptor. Since P2X7 receptor in macrophages is required for proper Nlrp3 inflammasome activation and for the production of mature, secreted IL-1 $\beta$, Aloe-mediated changes in the expression of the ATP-sensor may also contribute to its anti-inflammatory effect. Furthermore, the down-regulation of P2X7 may contribute to the substantially more pronounced reduction of the secreted IL-1 $\beta$ as compared to that detected in the intracellular protein level.

It is known that recognition of LPS by TLR4 stimulates downstream signaling pathways such as NF- $\mathrm{KB}$ and MAPKs (Akira and Takeda, 2004). In agreement with these reports, in our studies we found that LPS treatment of human macrophages induced the early activation of NF- $\kappa$ B, p38, JNK and ERK. NF- $\kappa$ B has been already reported to be involved in the expression of IL-1 $\beta$, Nlrp3 and caspase- 1 and studies on J774A.1 murine macrophage cell line described the significant regulatory role of MAPK signaling such as p38, JNK and ERK in the expression of IL-1 $\beta$ and inflammasome components (Bauernfeind et al., 2009; Qiao et al., 2012; Hsu and Wen, 2002; Liao et al., 2012). We found that Aloe vera treatment significantly inhibited the LPS-induced phosphorylation of $\operatorname{IkB} \alpha$, p38, JNK and ERK molecules. These results suggest that Aloe vera attenuates NLRP3 inflammasome, IL-1 $\beta$ and P2X7 receptor expression and ultimately IL-1 $\beta$ cytokine production via inhibiting these signal transduction pathways.

In conclusion, in this study we demonstrate that Aloe vera downregulates pro-inflammatory cytokine production in activated human macrophages and we provide possible molecular explanation on the observed phenomena. IL-1 $\beta$ together with TNF $\alpha$ are among the most powerful cytokines that under pathological conditions could cause cell degeneration and cell death resulting in multiple organ dysfunction (Tracey et al., 1987). Furthermore, as proximal cytokines, TNF $\alpha$ and IL-1 $\beta$ also stimulate the production of later or distal cytokines, such as IL-6 and IL-8 (Akira and Takeda, 2004). Interfering with the cytokine overproduction during early sepsis or in chronic inflammatory or autoimmune disease may improve the outcome and quality of life of patients. Therefore, Aloe vera could be a new therapeutic tool to target Nlrp3 inflammasome-mediated cytokine production.

\section{Acknowledgments}

The work was supported in part by the TÁMOP-4.2.1/B09/1/KONV-2010-0007 project (to J.T.), the TÁMOP-4.2.2.A$11 / 1 /$ KONV-2012-0023 (to S.B and J.T.), and the UD Faculty of Medicine Research Fund - Bridging Fund (to S.B.). A.V. is supported by the TÁMOP-4.2.2/B-10/1-2010-0024 project and TÁMOP-4.2.2.A-1/1/KONV-2012-0023. The project is co-financed by the European Union and the European Social Fund. S.B. is a receiver of Lajos Szodoray Postdoctoral Fellowship and Janos Bolyai Postdoctoral Fellowship.

\section{References}

Akira, S., Takeda, K., 2004. Toll-like receptor signalling. Nat. Rev. Immunol. 4, 499-511.
Barrantes, E., Guinea, M., 2003. Inhibition of collagenase and metalloproteinases by aloins and aloe gel. Life Sci. 72 (7), 843-850.

Bauernfeind, F.G., Horvath, G., Stutz, A., Alnemri, E.S., MacDonald, K., Speert, D. et al., 2009. Cutting edge: NF-kappaB activating pattern recognition and cytokine receptors license NLRP3 inflammasome activation by regulating NLRP3 expression. J. Immunol. 183, 787-791.

Cassel, S.L., Joly, S., Sutterwala, F.S., 2009. The NLRP3 inflammasome: a sensor of immune danger signals. Seminar Immunol. 4, 194-198.

Ciraci, C., Janczy, J.R., Sutterwala, F.S., Cassel, S.L., 2012. Control of innate and adaptive immunity by the inflammasome. Microbes Infect. 14, 1263-1270.

Dat, A.D., Poon, F., Pham, K.B., Doust, J., 2012. Aloe vera for treating acute and chronic wounds. Cochrane Database Syst. Rev. 2, CD008762.

Davis, R.H., Leitner, M.G., Russo, J.M., Byrne, M.E., 1989. Anti-inflammatory activity of Aloe vera against a spectrum of irritants. J. Am. Pediatr. Med. Assoc. 79, 263-276.

De Nardo, D., Latz, E., 2011. NLRP3 inflammasomes link inflammation and metabolic disease. Trends Immunol. 32, 373-379.

Dinarello, C.A., 1997. Interleukin-1. Cytokine Growth Factor Rev. 8, 253-265.

Dinarello, C.A., 2009. Immunological and inflammatory functions of the interleukin1 family. Annu. Rev. Immunol. 27, 519-550.

Dinarello, C.A., 2011a. Blocking interleukin-1beta in acute and chronic autoinflammatory diseases. J. Intern. Med. 269, 16-28.

Dinarello, C.A., 2011b. A clinical perspective of IL-1beta as the gatekeeper of inflammation. Eur. J. Immunol. 41, 1203-1217.

Duansak, D., Somboonwong, J., Patumraj, S., 2003. Effects of Aloe vera on leukocyte adhesion and TNF-alpha and IL-6 levels in burn wounded rats. Clin. Hemorheol. Microcirc. 29, 239-246.

Eamlamnam, K., Patumraj, S., Visedopas, N., Thong-Ngam, D., 2006. Effects of Aloe vera and sucralfate on gastric microcirculatory changes, cytokine levels and gastric ulcer healing in rats. World J. Gastroenterol. 12, 2034-2039.

Franchi, L., Munoz-Planillo, R., Nunez, G., 2012. Sensing and reacting to microbes through the inflammasomes. Nat. Immunol. 13, 325-332.

Gabay, C., Lamacchia, C., Palmer, G., 2010. IL-1 pathways in inflammation and human diseases. Nat. Rev. Rheumatol. 6, 232-241.

Grahames, C.B.A., Michel, A.D., Chessell, I.P., Humphrey, P.A., 1999. Pharmacological characterization of ATP- and LPS-induced IL-1 $\beta$ release in human monocyte. $\mathrm{Br}$. J. Pharmacol. 127, 1915-1921.

Gross, O., Thomas, C.J., Guarda, G., Tschopp, J., 2011. The inflammasome: an integrated view. Immunol. Rev. 243, 136-151.

Habeeb, F., Stables, G., Bradbury, F., Nong, S., Cameron, P., Plevin, R., et al., 2007. The inner gel component of Aloe vera suppresses bacterial-induced proinflammatory cytokines from human immune cells. Methods 42, 388-393.

Hamman, J.H., 2008a. Composition and applications of Aloe vera leaf gel. Molecules $13,1599-1616$

Hamman, J.H., 2008b. Composition and applications of Aloe vera leaf gel. Molecules 13 (8), 1599-1616.

Hsu, H.Y., Wen, M.H., 2002. Lipopolysaccharide-mediated reactive oxygen species and signal transduction in the regulation of interleukin-1 gene expression. J Biol. Chem. 277, 22131-22139.

Im, S.A., Lee, Y.R., Lee, Y.H., Lee, M.K., Park, Y.I., Lee, S., et al., 2010. In vivo evidence of the immunomodulatory activity of orally administered Aloe vera gel. Arch. Pharm. Res. 33, 451-456.

Juliana, C., Fernandes-Alnemri, T., Kang, S., Farias, A., Qin, F., Alnemri, E.S., 2012. Nontranscriptional priming and deubiquitination regulate NLRP3 inflammasome activation. J. Biol. Chem. 43, 36617-36622.

Karaca, K., Sharma, J.M., Nordgren, R., 1995. Nitric oxide production by chicken macrophages activated by Acemannan, a complex carbohydrate extracted from Aloe vera. Int. J. Immunopharmacol. 17 (3), 183-188.

Langmead, L., Makins, R.J., Rampton, D.S., 2004. Anti-inflammatory effects of aloe vera gel in human colorectal mucosa in vitro. Aliment. Pharmacol. Ther. 19 521-527.

Liao, P.C., Chao, L.K., Chou, J.C., Dong, W.C., Lin, C.N., Lin, C.Y., et al., 2012. Lipopolysaccharide/adenosine triphosphate-mediated signal transduction in the regulation of NLRP3 protein expression and caspase-1-mediated interleukin-1beta secretion. Inflamm. Res. 62, 89-96.

Lopez-Castejon, G., Brough, D., 2011. Understanding the mechanism of IL-1beta secretion. Cytokine Growth Factor Rev. 22, 189-195.

Menu, P., Vince, J.E., 2011. The NLRP3 inflammasome in health and disease: the good, the bad and the ugly. Clin. Exp. Immunol. 166, 1-15.

Netea, M.G., Nold-Petry, C.A., Nold, M.F., Joosten, L.A.B., Opitz, B., van der Meer, J.H.M., et al., 2009. Differential requirement for the activation of the inflammasome for processing and release of IL-1beta in monocytes and macrophages. Blood 113 , 2324-2335.

Park, M.Y., Kwon, H.J., Sung, M.K., 2011. Dietary aloin, aloesin, or aloe-gel exerts anti-inflammatory activity in a rat colitis model. Life Sci. 88, 486-492.

Prabjone, R., Thong-Ngam, D., Wisedopas, N., Chatsuwan, T., Patumraj, S., 2006. Antiinflammatory effects of Aloe vera on leukocyte-endothelium interaction in the gastric microcirculation of Helicobacter pylori-infected rats. Clin. Hemorheol. Microcirc. 35, 359-366.

Qiao, Y., Wang, P., Qi, J., Zhang, L., Gao, C., 2012. TLR-induced NF-kappaB activation regulates NLRP3 expression in murine macrophages. FEBS Lett. 586, 1022-1026.

Rathinam, V.A., Vanaja, S.K., Fitzgerald, K.A., 2012. Regulation of inflammasome signaling. Nat. Immunol. 13, 333-432.

Reuter, J., Jocher, A., Stump, J., Grossjohann, B., Franke, G., Schempp, C.M., 2008. Investigation of the anti-inflammatory potential of Aloe vera gel (97.5\%) in the ultraviolet erythema test. Skin Pharmacol. Physiol. 21, 106-110. 
Rey-Giraud, F., Hafner, M., Ries, C.H., 2012. In vitro generation of monocyte-derived macrophages under serum-free conditions improves their tumor promoting functions. Plos ONE 8, e42656.

Schroder, K., Sagulenko, V., Zamoshnikova, A., Richards, A.A., Cridland, J.A., Irvine, K.M., 2012. Acute lipopolysaccharide priming boosts inflammasome activation independently of inflammasome sensor induction. Immunobiology 217, 1325-1329.

Surjushe, A., Vasani, R., Saple, D.G., 2008. Aloe vera: a short review. Indian J. Dermatol. $53,163-166$

't Hart, L.A., Nibbering, P.H., van den Barselaar, M.T., van Dijk, H., van den Berg, A.J., Labadie, R.P., 1990. Effects of low molecular constituents from Aloe vera gel on oxidative metabolism and cytotoxic and bactericidal activities of human neutrophils. Int. J. Immunopharmacol. 12 (4), 427-434.

Tracey, K.J., Fong, Y., Hesse, D.G., Manogue, K.R., Lee, A.T., Kuo, G.C., et al., 1987. Anti-cachectin/TNF monoclonal antibodies prevent septic shock during lethal bacteraemia. Nature 330, 662-664. van't Wout, E.F., van Schadewijk, A., Savage, N.D., Stolk, J., Hiemstra, P.B. 2012. $\alpha 1$-Antitrypsin production by proinflammatory and antiinflammatory macrophages and dendritic cells. Am. J. Resp. Cell Mol. Biol. 5, 607-613.

Vazquez, B., Avila, G., Segura, D., Escalante, B., 1996. Antiinflammatory activity of extracts from Aloe vera gel. J. Ethnopharmacol. 55, 69-75.

Vijayalakshmi, D., Dhandapani, R., Jayaveni, S., Jithendra, P.S., Rose, C., Mandal, A.B., 2012. In vitro anti-inflammatory activity of Aloe vera by down regulation of MMP-9 in peripheral blood mononuclear cells. J. Ethnopharmacol. 141, 542-546. Vogler, B.K., Ernst, E., 1999. Aloe vera: a systematic review of its clinical effectiveness. Br. J. Gen. Pract. 49, 823-828.

Yu, C.S., Yu, F.S., Chan, J.K., Li, T.M., Lin, S.S., Chen, S.C., Hsia, T.C., Chang, Y.H., Chung, J.G., 2006. Aloe-emodin affects the levels of cytokines and functions of leukocytes from Sprague-Dawley rats. In Vivo 20 (4), 505-509.

Yun, N., Lee, C.H., Lee, S.M., 2009. Protective effect of Aloe vera on polymicrobial sepsis in mice. Food Chem. Toxicol. 47, 1341-1348. 